\title{
External Quantum Efficiency of a Solar Cell Zno/Cdte: Effect of Emitter and Base Thicknesses
}

\author{
${ }^{1}$ Moulaye Diagne, ${ }^{1}$ Nacire Mbengue, ${ }^{1}$ Mamadou Niane, ${ }^{2}$ Omar .A. Niasse, ${ }^{2}$ Bassirou Ba \\ (1) Laboratory of Semiconductors and Solar Energy, Physics Department, Faculty of Science and Technology, University Cheikh Anta \\ Diop, Dakar, Senegal \\ (2) Optoelectronic of semiconductor Faculty of Science and Technology, University Cheikh Anta Diop, Dakar, Senegal
}

\begin{abstract}
$\underline{\text { Abstract }}$
In this work, a study is carried out in view to investigate the influence of base and emitter thicknesses on the quantum efficiency of a $\mathrm{ZnO} / \mathrm{CdTe}$ solar cell. This quantum efficiency is a function of thicknesses of the $\mathrm{ZnO}$ transmitter and the CdTe base. This study allows to make choice on values of the thicknesses of $\mathrm{ZnO}$ and CdTe appropriate to optimize the performance of the solar cell.

\section{Keywords:}

Solar cells, Zinc oxide, Telluride of cadmium, Quantum efficiency, Absorption coefficient, Refraction index.
\end{abstract}

\section{INTRODUCTION}

The principal cause limiting the performance of solar cells is the recombination of charge carriers photogenerated in the active base region. The key parameters, such as base and emitter thicknesses, are of great importance when designing these optoelectronic devices. O.A. Niasse et al [1], S.Z. Karazhanov et al [3] have studied theoretically the behavior of the devices governed by the complexity of electronic interactions which are modified by the crystalline defects, level doping, free charge carriers and elementary excitation.

In this paper, the influence of the emitter and base thicknesses on the quantum efficiency of the $\mathrm{ZnO} / \mathrm{CdTe}$ heterojunction is examined. Before making this study, the refractive index, the reflection and absorption coefficients, are examined owing to the fact that they are important parameters of the heterojunction. The contributions to the spectral response of various parts of the solar cell is also investigated.

\section{THEORY}

It will be considered that minority carriers transport is done only along one direction perpendicular to the junction. The quantum efficiency will be calculated using a onedimensionnal modelas shown on the Fig. 1.

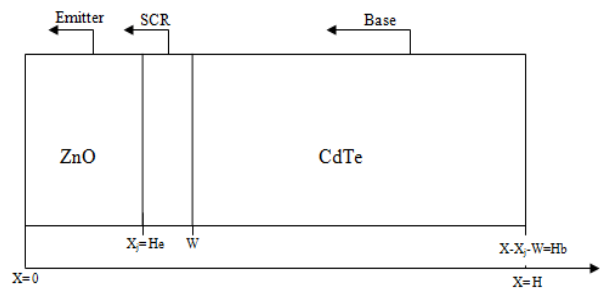

Fig. 1. Diagram of the $\mathrm{ZnO} / \mathrm{CdTe}$ heterojunction.

S. Girish [4], A.E. Rakhsni [5] showed that the CdTe semiconductor is the active zone of the $\mathrm{ZnO} / \mathrm{CdTe}$ heterojunction where the majority of the minority carriers is generated.

T.K. Subramanyam [6] showed that $\mathrm{ZnO}$ emitter is the window layer with a thickness greater than that of CdTe.

H. Yoshikawa [7], S. Adachi [8] studied respectively the refractive index, reflection coefficient and absorption coefficient on the devices $\mathrm{ZnO}$ and $\mathrm{CdTe}$.

\section{RESULTS AND DISCUSSIONS 3.1 REFRACTIVE INDEX}

On Fig.2, it is noted that the refractive index increases gradually in the interval of energy $1.5 \mathrm{eV}-2 \mathrm{eV}$ from $n=1.86$ to $\mathrm{n}=1.99$. This variation is followed in the vicinity of $3.4 \mathrm{eV}$ (gap of zinc oxide), by a peak laying from $n=1.99$ to $n=2.37$. The peak is followed by a short increase from $n=1.80$ to $n=$ 1.83 .

H. Yoshikawa et al [7] showed that the increase of refractive index noted in the vicinity of the gap can be explained by the fact that all the photons which arrive in this zone are absorbed because the material is transparent in this interval of energy. The significant peaks also observed are mainly due to the transition from the discrete exciton.

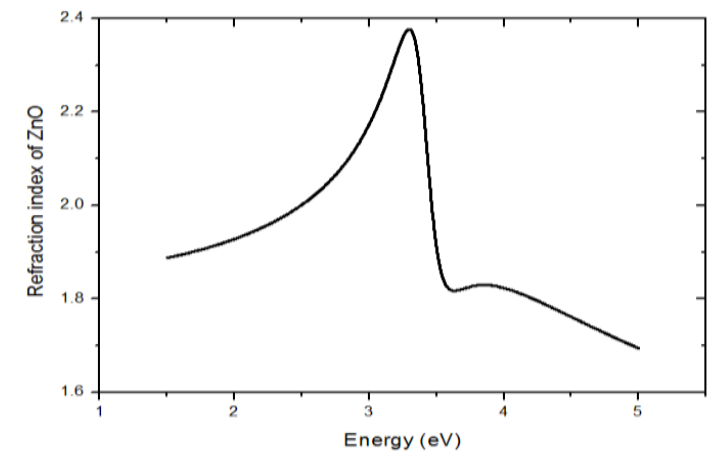

Fig. 2. Variation of the refraction index of $\mathrm{ZnO}$ according to the energy of incident photons 


\subsection{REFRACTION COEFFICIENT}

The Fig. 3 shows the evolution of the reflection coefficient of $\mathrm{ZnO}$ and CdTe calculated from Adachi method [ ].

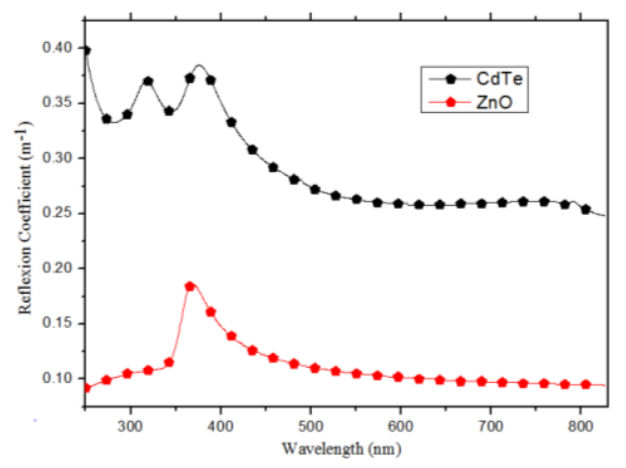

Fig. 3. Variation of the reflection coefficient

of $\mathrm{ZnO}$ and $\mathrm{CdTe}$ with wavelength

It is noted that on all the wavelength range, the reflectivity of the cadmium tellurium is greater than that of zinc oxide with a maximum value $\mathrm{R}=0.40$ for $\mathrm{CdTe}$ and 0.17 for $\mathrm{ZnO}$. This is explained by the fact that CdTe is active in all this interval. On the other hand, H. Abdelkader [9], M. K. Khalaf [10] showed that $\mathrm{ZnO}$ is transparent for energy exciton less than $3.5 \mathrm{eV}(360 \mathrm{~nm})$.

The reflectivity for the two materials varies smoothly for visible light $(380 \mathrm{~nm}-850 \mathrm{~nm})$.

\subsection{ABSORPTION COEFFICIENT}

The absorption coefficient of the semiconductors are displayed on Fig 4.

The results showed that the absorption coefficient for CdTe is higher on all wavelength the range than that of $\mathrm{ZnO}$. This phenomenon is justified by the fact that the CdTe gap at 840 $\mathrm{nm}$ given by ref [12] is greater than that of $\mathrm{ZnO}$ which is 340 nm [13] because absorption coefficient is very weak with energies of the photons close to the gap of material. Conversely the absorption becomes significant for photons with wavelengths lower than the bandgap wavelength of the material.

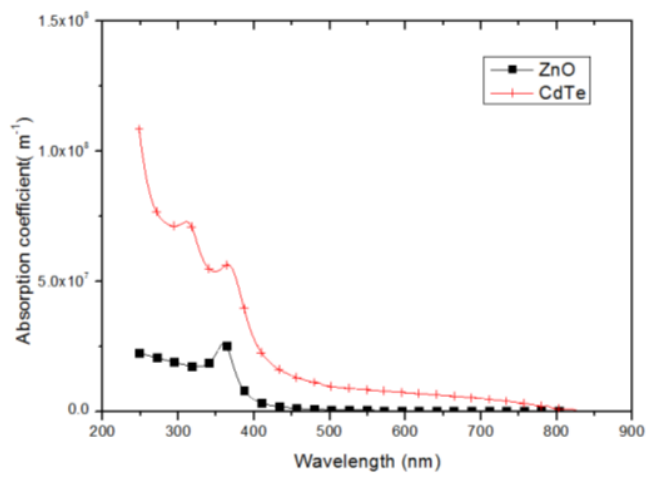

Fig. 4. Variation of the absorption index of $\mathrm{ZnO}$ and $\mathrm{CdTe}$ according to the wavelength
In addition, it is noted that for $\mathrm{ZnO}$, that absorption coefficient decreases gradually from $200 \mathrm{~nm}$ to $376 \mathrm{~nm}$. The low values of the absorption coefficient for $\mathrm{ZnO}$ in energy values lower than $3.33 \mathrm{eV}$ prevents from absorption of photons with energy lower than $\mathrm{ZnO}$ bandgap. Consequently, this make $\mathrm{ZnO}$ transparent to the visible light. L. Atourki et al [14] used transparent $\mathrm{ZnO}$ electrodes for the solar cells.

\subsection{QUANTUM EFFICIENCY}

The quantum efficiency of $\mathrm{ZnO} / \mathrm{CdTe}$ solar cell is given by the sum of quantum efficiency of the base, the emitter and the space charge region.

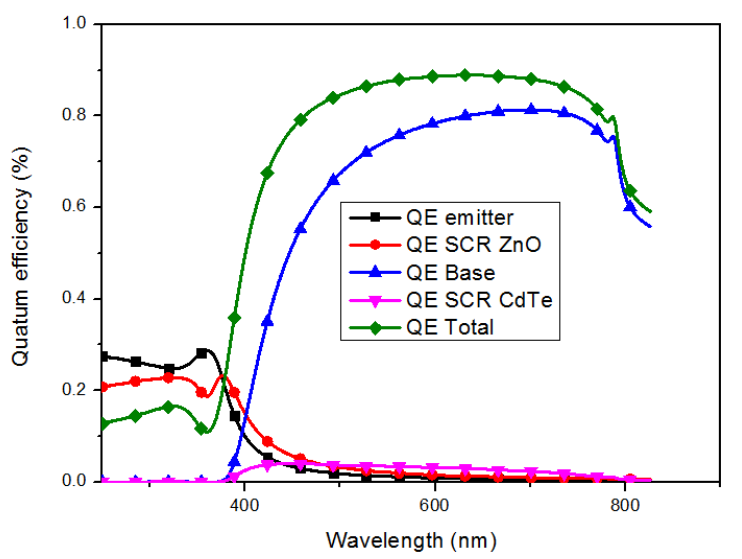

Fig. 5. Variation of the quantum efficiency according to the wavelength The Fig. 5 shows that the different parts of the cell contribute to the spectral response of the $\mathrm{ZnO} / \mathrm{CdTe}$ heterojunction. However it is noted that the emitter and the space charge region participate only in the wavelengths ranging from 250 to $400 \mathrm{~nm}$ corresponding to high energy photons. The base intervenes in long wavelengths range with energy close to the gap. It is noted that $\mathrm{ZnO}$ emitter and the space charge regions exhibit quantum efficiencies greater than $20 \%$ for wavelengths lower than $400 \mathrm{~nm}$. The CdTe base and space charge region do not contribute in this wavelength range because of photons absorption in the $\mathrm{ZnO}$ layer.

It is also noted that the total efficiency varies from $67 \%$ to $92 \%$ for wavelengths ranging between $255 \mathrm{~nm}$ and $463 \mathrm{~nm}$. This increase is due to photons energy higher than bandgap $\mathrm{E}_{\mathrm{g}}$. On the other hand, the reduction in the total output can be explained by the decrease of absorption coefficient and the increase of reflection on emitter surface. The number of incidental photons reflected increase what has as a consequence in a weak absorption for the device as shown in Fig. 2.

Indeed, all curves show peaks between $338 \mathrm{~nm}$ and $362 \mathrm{~nm}$ (i.e. $3.43 \mathrm{eV}-3.67 \mathrm{eV}$ ) which show the excitons effects in $\mathrm{ZnO}$ close to the band gap energy. 


\subsection{INFLUENCE OF EMITTER AND BASE THICKNESSES}

For better illustrating the effects of emitter and base thickness on quantum efficiency, a series of curves is displayed on figures 5 and 6 .

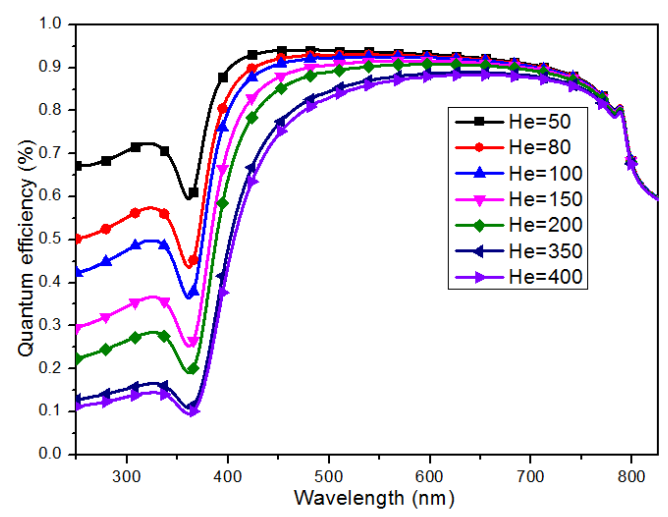

Fig.7. External quantum yield according to the wavelength for various values of emitter thickness.

A numerous works [15 - 17] showed that $\mathrm{ZnO}$ is the window layer in the heterojunction $\mathrm{ZnO} / \mathrm{CdTe}$; this denomination refers to the property of transparency of $\mathrm{ZnO}$ layer which depends on the thickness as shown in fig 5. For a constant base one.

The Fig.5 shows the profiles of external quantum efficiency according to incident photons wavelength for different values of the thickness of $\mathrm{ZnO}$ layer.

The $\mathrm{ZnO}$ thickness is more sensitive in wavelength ranging from 300 to $500 \mathrm{~nm}$ corresponding to the contribution of the emitter and the space charge region. As the emitter thickness increases from $50 \mathrm{~nm}$ to $400 \mathrm{~nm}$, the maximum quantum efficiency located at $320 \mathrm{~nm}$ decreases from $67 \%$ to $17 \%$. The emitter thickness also degrades the base contribution in wavelength range from $350 \mathrm{~nm}$ to $700 \mathrm{~nm}$ due to weaker absorption photon flux reaching the base region according to Lambert law as the emitter thickness increases.

It is noted that these profiles of efficiency take the same forms. For a given curve quantum efficiency increases when the wavelength believes. This corresponds to a good absorption of the $\mathrm{ZnO}$ layer because the energy of the incidental photons of which the wavelengths lie between $380 \mathrm{~nm}$ and $500 \mathrm{~nm}$, is higher or equal to the energy of gap of $\mathrm{ZnO}$.

In the interval wavelength ranging between $500 \mathrm{~nm}$ and 800 $\mathrm{nm}$, external quantum efficiency decreases. The energy of the incidental photons is lower than that of the gap $\mathrm{ZnO}$ : the layer of $\mathrm{ZnO}$ becomes increasingly transparent with the wavelength. The base of $\mathrm{ZnO} / \mathrm{CdTe}$, the most active region of the cell, represents the important part of the quantum efficiency. It is responsible of the photocurrent in the cell and for this it is necessary to examine its thickness influence on the cell efficiency.

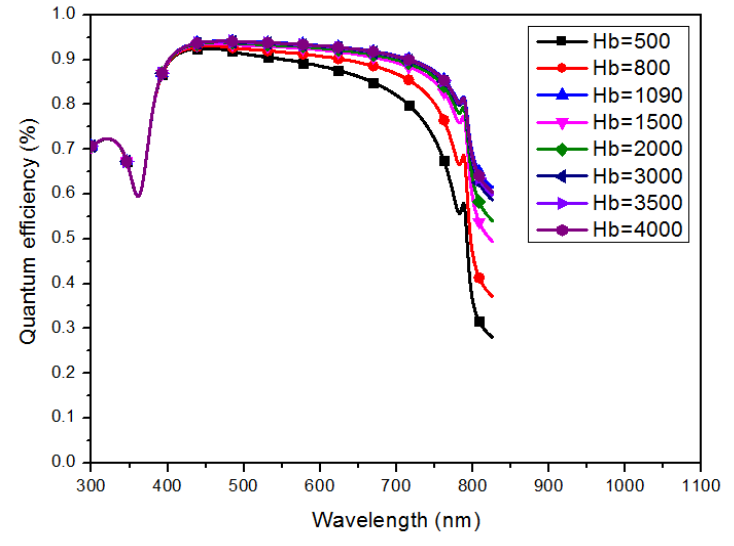

Fig. 6. Quantum efficiency as a function of wavelength for different values of base thickness

The Fig. 6 shows the profile of quantum efficiency according to the wavelength of the incident photons for various thicknesses of the CdTe layer.

For a curve corresponding to a given thickness of CdTe, quantum efficiency increases in the interval wavelength ranging between $360 \mathrm{~nm}$ and $428 \mathrm{~nm}$.

In the interval wavelength ranging between $400 \mathrm{~nm}$ and 700 $\mathrm{nm}$, the quantum efficiency increases with base thickness lower than $1000 \mathrm{~nm}$. This increase is explained by a more uniform generation of carriers which take place for long wavelengths. For base thicknesses greater than 1000 nm, no influence is observed on quantum efficiency.

In the interval wavelength ranging between $700 \mathrm{~nm}$ and 800 $\mathrm{nm}$, quantum efficiency decreases corresponding to photons energy are lower than the energy of the gap of CdTe, the CdTe layer becomes transparent with the long wavelengths. For thicknesses lower than $430 \mathrm{~nm}$, no effects of the base is observed, only emitter thickness governed the behavior of the cell.

\section{CONCLUSION}

In this work, optical parameters like refractive index, reflection and absorption coefficients, absorption of the materials devices constituting the $\mathrm{ZnO} / \mathrm{CdTe}$ heterojunction are examined through their variation with incident photons wavelength. The contribution of the different parts of the cell on quantum efficiency are studied for different values of emitter and base thicknesses.

The results showed that the efficiency increases according to the thickness of the base and it decreases conversely according to the thickness of the transmitter. The result showed that for a good optimization of the efficiency of the solar cell $\mathrm{ZnO} / \mathrm{CdTe}$, thin thickness of the emitter must be chosen at about $50 \mathrm{~nm}$ if technical process enable this. 


\section{References}

[1] O.A. Niasse, B. Mbengue, B. BA, A. Ndiaye, I. Youm, Effets of excite on the quantum efficiency of the solar cell CdS/CdTe by the model of the dielectric function, Review of Renewable Energies. vol. 12 n. 3, 2009, pp. $501-512$.

[2] S. Z. Karazhanov, Y. Zhang, A .Mascarenhas, S. Deb, The effect of excitons on CdTe Solar Cells, Journal of Applied Physics, vol. 87, n. 12, 2000, pp. 8786-8792.

[3] S. Girish Kumar, K. S. R. Koteswara, Physics and chemistry of $\mathrm{CdTe} / \mathrm{CdS}$ thin film Heterojunction Photovoltaic Devices, Fundamental and Critical Aspects Energy Environmental, vol. 7, 2014, pp .45-102

[4] A. E. Rakhsni, Heterojonction Properties of Electrodeposited CdTe/CdS Solar Cells, Journal of Applied Physics, vol. 90, n. 8, 2001, pp. 4265-4271.

[5] T.K. Subramanyam, B. Srinivasulu Naidu, S. Uthanna, P.F. Gerhardinger, R. J. Mc Curdy, Thin Films for Photovoltaic and Related Device, Crystal Resarch Technologies, vol. 35, 2000.

[6] H. Yoshikawa, S. Adachi, Optical constant of $\mathrm{ZnO}$, Journal of Applied Physic, vol. 36, 1997, pp. 6237-6243.

[7] S. Adachi, N. Kimura and N. Suzuki, 'Optical Properties of CdTe: Experimental Modelling',Journal of Applied Physics, vol. 74, n. 5,1993 , pp. 3435-3441

[8] H. Abdelkader, Y. Fayssal, D. Warda, A. Nadhiret, A. M .Salah, Revue Nature et technologie, vol. $\mathrm{n}^{\circ}$ 06, Janvier 2012, pp. 25-27.

[9] M. K. Khalaf, A. Hussain, K.Iltaif, N. M.Hadi, R. H. Jabaar, A. A. Jabor, M. A. Abood, S. S. Botress, A. A. Ali, Characteristics of Zinc Oxide Film Prepared by Chemical Spray Deposition as a Gas Sensor, Iraqi Journal of Physics, Vol. 9, n. 9, 2011, pp. $25-30$.

[10] M. Gloeckler, J.R. Sites, Apparent Quantum Efficiency Effects in CdTe Solar Cells, Journal of Applied Physics, Vol. 95, n. 8, 2004, pp. $4438-4445$

[11] D. Soro, B. Mari, B. Aka, Study of the Composition Stæchiométrique of the Thin Coats(Layers) of CdTe Developed by Electroplating for Photovoltaic Applications, Afrique Science, vol. $6, \mathrm{n} .2,2010$, pp. 1-8.

[12] V. Srikant, D. R. Clarke, On the Optical band gap of Zinc Oxide, Journal Applied Physics, vol. 83, n. 10, 1998,pp. 5447-5451.

[13] L. Atourki, K. Bouabid, E. Ihalane, L. Alahyane, H. Kirou, E. El Hamri, A. Ihlal? A. Elfanaoui, L.Laanab, Pulse Electrodeposition of $\mathrm{ZnO}$ for thin Absorber Solar cells,Energy Procedia,vol. 50,2014, pp. 376-382.

[14] Ü. Özgür, Y. I. Alivov, C. Liu, A. Teke, M. A. Reshchikov, S. Doğan, V. Avrutin, S.-J. Cho, H. Morkoç, Comprehensive Review of $\mathrm{ZnO}$ Materials and Devices. Journal Applied Physics, vol. 98, n. , 2005, pp. 1-103.

[15] C. C. Kuo, C. C. Liu, S. Chih He, J.T. Chang, J.Liang He, The Influences of Thickness on the Optical and Electrical Proprieties of Dual Ion-Beam Sputtering Deposited Molybdenum Doped Zinc Oxide Layer, Journal of Nanomaterials, vol. 2011, Article ID 140697, pp. 1-5.

[16] J. A. Aranovich, D. Golmayo, A. L. Fahrenbruch, R. H. Bube, Journal of Applied Physics, vol. 51,n. 8, 1980, pp. 4260-4268. 